https://doi.org/10.30681/real.v14.4894

\title{
A METAFORIZAÇÃO DA MULHER NO FUNK: MOÇA E MINA NO DISCURSO
}

\author{
Leandro Dias SALVATERRA (UNEMAT) ${ }^{1}$
}

\begin{abstract}
Resumo: Com este trabalho pretendemos refletir e compreender as terminologias que vêm se discursando a respeito da mulher nas letras de funk, atentando-se ao processo de metaforização e sua relação na constituição do sujeito mulher. Contempla-se o trabalho sob a perspectiva teórica da Análise do Discurso de linha francesa. Percebemos, portanto, que moça e mina ocupam nas letras analisadas espaços distintos, e esse processo se dá pela relação do sujeito com a história e do discurso com a história, pautado na metáfora.
\end{abstract}

Palavras-chave: Mina. Moça (de fé). Metaforização.

Abstract: With this work we intend to reflect and understand the terminologies that are being discussed about women in funk lyrics, paying attention to the process of metaphorization and its relationship in the constitution of the woman subject. The work is contemplated under the theoretical perspective of the Discourse Analysis of the French line. We perceive, therefore, that girl and mine occupy different spaces in the analyzed letters, and this relationship occurs through the subject with the story and the discourse with the story, based on the metaphor.

Keywords: Mine. Girl (of faith). Metaphorization.

\section{Introdução:}

Pela perspectiva teórica da Análise de Discurso de linha francesa, buscamos observar e discutir as designações que constituem a mulher enquanto sujeito do funk, por meio de metáforas em funcionamento nas letras musicais e, assim, compreendermos os efeitos de sentidos produzidos. Pretendemos também observar como esses sentidos (re)significam o sujeito, atribuindo-lhe uma identidade imaginária com a qual supostamente se identifica.

Vimos que as designações referentes à mulher são várias, como mina (que diz respeito à puta) e moça (como mulher de família). Como suporte teórico, para sustentar nossa proposta, dialogaremos com o texto Na batida da cachorra (2005), de Guimarães, Exterioridade e ideologia (1996) e Princípios e procedimentos (2009), da Orlandi e alguns outros textos que se mostraram pertinentes para a discussão. Por meio desses estudiosos, buscamos compreender melhor o nosso material de análise, como dito de antemão, as letras de funk, as quais produzem

\footnotetext{
${ }^{1}$ Graduado em Letras pela Universidade do Estado de Mato Grosso (UNEMAT), campus de Pontes e Lacerda, Mato Grosso, Brasil. E-mail: 1d11071998@gmail.com
} 
sentidos para o sujeito mulher em certas condições de produção. Ainda, atentaremos à posição discursiva desses dizeres metafóricos sobre/para a mulher.

Antes de principiar a análise, a nossa materialidade se torna importante para evidenciar essa posição e identidade atribuída pelas canções ao sujeito em análise. Eni Orlandi afirma que “já faz entrada, assim, desde o início, uma noção teórica, a de materialidade, definida na ordem do discurso como forma material, relação da ordem simbólica com o mundo". (ORLANDI, 1996, p.28). Como afirmado pela autora, e assim será em nossa análise, as letras musicais que trouxemos à discussão serviram de espaço simbólico para com o mundo e a situação presente, permitindo-nos proceder com a análise.

\section{Análise das terminologias mina e moça nas letras de funk}

O funk propriamente dito e de acordo com o site Brasil Escola, surgiu por meio das músicas negras norte-americanas no final da década de 1960, entretanto, com o passar do tempo, o funk veio adquirindo um ritmo mais acelerado, ganhando e se fixando enquanto gênero e ritmo dançante. Neste passar de tempo, o conteúdo exposto em suas letras servia para contextualizar o local e a vida de moradores de favela, nisso, já na cidade do Rio de Janeiro, por volta de 1980. A seguir, transcrevemos a letra da música Rap da felicidade, dos compositores Cidinho e Doca, que em ritmo de funk retrata a vida dos moradores das periferias, o desrespeito, a violência, o medo, vejamos um trecho:

"Eu só quero é ser feliz,

Andar tranquilamente na favela onde eu nasci,

E poder me orgulhar,

E ter a consciência que o pobre tem seu lugar..."

“(...) Minha cara autoridade eu já não sei o que fazer

Com tanta violência eu sinto medo de viver

Pois moro na favela e sou muito desrespeitado

A tristeza e alegria que caminham lado a lado (...)" 
Como se pode observar, o funk, a partir da década de 80, no Rio de Janeiro, tinha como objetivo mostrar a realidade das favelas e de seus moradores, como mostra a letra acima, que perceptivelmente não era nada agradável, pois o perigo e o medo andavam lado a lado. Mais adiante, as letras passaram a ganhar um outro espaço, o de falar sobre a mulher e constituir sujeitos por outros dizeres, o dizer metafórico.

Principiando pelo MC MM, com o funk Adestrador de cadela, observemos a letra:

Sabe aquelas minas cachorra, piranha, sapeca,

Então pode trazer elas que R7 dá um trato,

Põem no pelo e goza nela,

Então cancela as moças de família certa,

Que minha meta na favela é só pegar mina perversa...

Observando os sentidos diferentes de mina e moça, mina é comparada à cachorra, piranha e sapeca, já moça, a construção foi semanticamente elaborada dentro do contexto desejado, em se tratando da distinção dos tipos de mulheres que constituem as letras de funk, a partir da visão do homem, já que que podemos comparar ao ditado "bela, recata e do lar", que seria moça de família. Essa por sua vez é excluída do universo metafórico, e incluída no universo padrão e familiar. Já aquela, é incluída no universo metafórico e excluída do universo padrão e familiar. Além disso, a construção simbólica do espaço é marcante, pois podemos depreender que é na favela/periferia que elas (minas) se encontram.

Antes de tudo, lembramos que a metaforização que buscamos observar não é aquela mesma/presente na literatura, mas sim a própria da Análise de Discurso. Luciana Leão Brasil (2011, p. 9) afirma que “em Análise de Discurso, a metáfora não funciona como comparação ou substituição. A metáfora em análise do discurso funciona como transferência que se produz num processo intermitente entre deslizamentos de sentidos". Com base nessa perspectiva que procederemos a análise das terminologias moça/mulher de fé e mina, e assim entender os seus efeitos de sentidos produzidos.

Outros trechos de funk que fazem a mesma abordagem são os do MC NUNO DV, Ela é maior piranha; Do MC Kapela MK, Mais que dinheiro, e do MC MM, Piranha das braba. Vejamos os respectivos trechos que abordam tais termos: 
"Não cola com essa mina que ela é maior piranha (...)

Não traia sua mulher de fé, que fecha contigo o ano inteiro

E pare de gastar dinheiro na mimosa e no puteiro (..)"

MC NUNA DV

"Dinheiro traz piranha, e não atrai mulher.

Dou valor pra minha de fé, família e parceiros (...)"

MC Kapela MK

“(...) Ó que piranha abusada

Veio na banca dos quebrada

E falou pra vagabundo

Que ela é moça de casa

Ah... Para!

Eu sei que tu é danada (...)"

MC MM

Como apresentado, moça ocupa um espaço simbólico no funk, assim como a terminologia mina, espaços esses distintos, mas que se significam. Orlandi afirma que "o sentido é assim uma relação determinada do sujeito— afetado pela língua- com a história." (ORLANDI, 2009, p.47), ou seja, o sentido produzido pela letra, principalmente por essa mina metaforizada, acaba sendo determinado pelo próprio sujeito na história.

Como também podemos observar, não é somente a terminologia moça que se refere às moças de família, temos a expressão mulher de fé, que carrega o mesmo valor semântico. Guimarães (2005), ao tratar do termo “mulher/mina de fé", trata essa definição como a mulher fiel, que não trai. E afirma que dessa maneira vai se formando vários sentidos que vão se instalando sobre a mulher a partir da fala do homem.

Mas aí questionamos, até que ponto se considera essa metaforização? Buscaremos responder a essa pergunta no decorrer de nossa análise. A mina, ao ocupar sentidos metafóricos, 
a sociedade enquanto sujeito-público é apenas alvo desse deslizamento de sentido, uma vez que as nomenclaturas são colocadas e constituídas por sentidos que causam efeitos diferentes, instalando-os no imaginário do sujeito. Cachorro (a), como sabemos, é um animal dócil, amigo, companheiro; já piranha é um animal ágil, e como se pode observar, no gênero funk, há esse deslizamento semântico, em que o sentido do animal passa a ser pejorativo, excluindo o sentido dócil e sobressaindo o mais obsceno, e como afirma Eni Orlandi (2007), "esse fato possibilita a ruptura, mostrando que o sentido pode ser outro.”, ou seja, os animais citados nas letras das músicas funk ocupam semanticamente um outro sentido, discorrido e constituído por sua vez por meio da relação do discurso com a história.

Já mulher de fé, termo também usado para denotar princípios femininos, acaba obtendo uma constituição de sentido dado historicamente ao sujeito, pois, ao observarmos a terminologia, podemos de início associar/relacionar a mulheres religiosas, que creem em algo, entretanto, não é este o sentido empregado nas letras musicais, mas que pode, a certo ponto, ter uma pequena influência, já que mulher de fé, analisando pelo pensar religioso, seria uma mulher doutrinada, certa, com valores morais e sociais. Aline Fernandes de Azevedo (2014, p. 5) afirma que "a metáfora é situada, desta forma, em relação ao discurso do inconsciente, introduzindo o paradoxo de um discurso duplo e uno [...]". Neste caso, haverá um duplo sentido, mas que apenas um se fixará e de maneira paradoxal e inconscientemente.

Ambas terminologias fazem criar um imaginário de mulher na visão masculina e do sujeito-público, reiteramos que esse fator se deu no decorrer da história, possibilitando por sua vez esse deslizamento semântico, que é o processo da mina metaforizada. Orlandi (1996) vai dizer que "as posições do sujeito são uma função da relação da língua com as formações sociais em seus mecanismos de projeção imaginários. Como a ordem da língua e a ordem do mundo não são coincidentes, elas só funcionam pelo imaginário". Ou seja, a formação do imaginário, de acordo com Orlandi, se dá pela função social desempenhada pelo sujeito na sociedade.

É importante mencionar que essa caracterização e deslizamento de sentido (res)significam a mulher em duas concepções, vejamos por um breve quadro:

Mulher de fé/moça
Mulher de família (mulher não metaforizada) 


\begin{tabular}{|l|l|}
\hline Mina & $\begin{array}{r}\text { Mulher metaforizada (cachorra, } \\
\text { piranha, puta) }\end{array}$ \\
\hline
\end{tabular}

Como se pode perceber, a constituição destas terminologias no espaço simbólico (funk) se dá por esse deslizamento semântico proposto a ser observado. E das músicas analisadas, moça é uma palavra sutil com relação ao significado, que ao escolherem, o sentido foi bastante preciso para evidenciar aquilo que foi desejado. Já mina, terminologia recente e usada por grande parte dos adolescentes, trouxe juntamente com o funk um sentido já constituído pelo próprio discurso nos dizeres dos cantores deste gênero, cujo nome em si já carrega semanticamente sentidos diversos, e dentre esses sentidos diversos, maioria faz produzir um imaginário da/sobre mulher. Orlandi (2009) afirma que "as palavras falam com outras palavras. Toda palavra é sempre parte de um discurso. E todo discurso se delineia na relação com outros: dizeres presentes e dizeres que se alojam na memória.”, ou seja, uma palavra se comunica com outra, sendo parte de um discurso, neste caso, o que pretendeu o funk, e isso se dará por dizeres presentes (nas letras musicais) e o da memória, criando por consequência o imaginário.

M. Pêcheux (1975 apud Orlandi 2009) afirma que podemos distinguir duas formas de esquecimento no discurso, o de número dois é a paráfrase (consciente) e a de número um é a polissemia (inconsciente). Destes dois, ficamos com a polissemia, que é um esquecimento ideológico, o qual segundo Orlandi, temos neste a ilusão de sermos a origem daquilo que dizemos, sendo que na verdade retomamos sentidos já existentes. E que em relação ao funk, o que irá constituir a mulher, assim como qualquer outro sujeito e sentido, e que dizemos ser necessário, é a língua e a história. Pois no funk, adquirimos inconscientemente a imagem de mina igualmente àquilo que foi descrito pela letra do funk, sendo que na verdade, foi um processo metafórico que constituiu gradativamente na relação histórica e discursiva, que poderia ter um sentido diferente daquele já constituído, mas que juntamente com o espaço de relação entre mina e moça, acabou contribuindo, assim como outros fatores, para esse sentido fixado.

\section{Conclusão}

Por fim, essa pesquisa nos permitiu constatar que mina e moça ocupam espaços e sentidos diferentes (efeitos de sentidos) dentro das letras de funk, e que essa constituição se dá pela 
própria relação do sujeito com a história e do discurso com a história, como enfatizamos anteriormente. Assim como também por meio da relação dicotômica, maniqueísta, que acaba criando inconscientemente esse espaço significante de distinção entre as terminologias, Eni Orlandi (2009) considera que "os sentidos não estão nas palavras elas mesmas. Estão aquém e além delas" (ORLANDI, 2009, p.42), ou seja, o sentido também é adquirido e criado pelo sujeito, não estando apenas o significado pretendido nas palavras. Enfatizamos, portanto, que o sentido poderia ser outro, como dito, cachorro é um animal dócil, companheiro; já piranha, um animal ágil, para tanto, os sentidos impregnados se deram pela metaforização /deslizamento de sentido criado ideologicamente (polissemia) pelo sujeito e a história, e que este sentido poderia ser outro atribuído, mas que não foi o caso nas letras analisadas.

\section{Referências}

AZEVEDO, Aline Fernandes de. Sentidos do corpo: metáfora e interdiscurso. Campinas, São Paulo, 2014

BRASIL, Luciana Leão. Deslizamento de sentidos por efeitos metafórico: o discurso de uma fotografia. Revista Rua, Campinas, 2007

DANTAS, Tiago. "Funk"; Brasil Escola. Disponível em <http://brasilescola.uol.com.br/artes/funk.htm>. Acesso em 14 de Dezembro de 2017.

ORLANDI, E. As formas de silêncio: no movimento dos sentidos. Campinas: Editora da Unicamp, 2007

Princípios e procedimentos. Pontes: 2009

Exterioridade e ideologia. Cad. Est. Ling., Campinas, (30):27-33, Jan./Jun. 1996

GUIMARÃES, Eduardo. "Na batida da cachorra" in: Escritos 9. Dez, 2005 